\title{
Some Features of Es-Ionization of the Equatorial Ionsphere
}

\author{
P. Bandyopadhyay and H. Montes
}

\author{
Contribution From Huancayo Observatory, Instituto Geofísico del Perú, Huancayo, Perú
}

(Received May 6, 1964)

\begin{abstract}
This paper, extension of an earlier work [Bandyopadhyay and Montes, 1963], examines certain features of the $c$ - and the $h$-type of sporadic $E$ from the data of some South American stations near the magnetic equator. The features examined include diurnal, seasonal, and lunar variation of occurrences and correlations with geomagnetic disturbances. The occurrences of both $E s-c$ and $E s-h$ are found to correlate with magnetic dip, being most infrequent near the magnetic equator.

The paper also examines the results of an equatorial VHF forward seatter experiment and compares them with certain features of $E s-q$ noted before from Huancayo ionograms and reported in the earlier work. The close agreement observed suggests that the irregularities of ionization which manifest themselves in the two different kinds of observations are either the same or have a common origin.
\end{abstract}

\section{Introduction}

According to the classification of sporadic $E$ introduced during the IGY one can recognize six different types of $E s$ from the ionograms obtained at stations located in the (magnetic) equatorial region. These are $q_{-}, s_{-}, l_{-}, f_{-}, c_{-}$, and $h$-type. In an earlier study [Bandyopadhyay and Montes, 1963] some features of $q_{-}, l-$, and $f$-types were examined from the routine Es data of the South American chain of transequatorial stations roughly along the $75^{\circ} \mathrm{W}$ meridian. Here are presented the results of an examination of the remaining types $c$ and $h$ with the equatorial $s$ type, which has been shown [Cohen, Bowles, and Calvert, 1962] to be another manifestation of the same irregularities that give rise to the $q$-type trace, excluded from the study. The features of $E s-c$ and $E s-h$ examined are diurnal and seasonal variation of occurrences, lunar effects, and correlation with geomagnetic disturbances.

During the IGY a number of VHF forward scatter propagation paths were established near the magnetic equator in South America under a co-operative experimental program of the U.S. National Bureau of Standards with the Instituto Geofísico del Perú and a few other organizations [Cohen and Bowles, 1963b]. The principal interest in these experiments was to study the special kind of electron density irregularities of the equatorial ionosphere which were believed to manifest themselves in a number of phenomena such as the equatorial type sporadic $E(E s-q)$, spread $F$, etc. As a result of these experiments, a close association was noticed between (a) the fluctuations of the E-region scatter signal, (b) the occurrences of $E s-q$ in Huancayo ionograms, and (c) the magnetic manifestations of the equatorial electrojet which is believed to be the cause of the irregularities. Numerous features of this asso- ciation have already been discussed [Bowles and Cohen, 1962; Cohen and Bowles, 1963b; Bowles, Balsley and Cohen, 1963; Bandyopadhyay and Montes, 19631. The present paper adds a few more to the correlations observed between (a) and (b).

\section{Occurrences of $E_{S-c}$ and $E_{S}-h$}

The average occurrences of the $c$ - and the $h$-type sporadic $E$, at different hours of the day and in different seasons $(J, E$, and $D$ months of 1958), are shown in figures 1 and 2 . The diurnal variations of either type, during December solstice months, are characterized by the occurrence of two peaks, one in the morning around $08 \mathrm{hr}$ and the other in the afternoon around $16 \mathrm{hr}$. In other seasons, particularly during the June solstice months at Talara, Chiclayo, and Chimbote, only one of these peaks is usually prominent. It will also be noticed from the above figures that the occurrences of these two types of sporadic $E$ show some correlation with dip, being less frequent at Huancayo and Juliaca near the dip equator. (Note the different ordinate scale for Huancayo and Juliaca in fig. 1.)

This correlation with dip is more clearly shown in figure 3 which is a plot of average hourly occurrence (averaged over the hours 05 through 20) of $E s-c$ and $E s$ - $h$ during equinox months, against the dip values of the respective stations. Knecht and McDuffie (1962) have found that the occurrences of the blanketing type of sporadic $E$ decreases sharply near the magnetic equator. For example, they observed that the occurrence of blanketing by $E$ s to frequencies greater than $5 \mathrm{Mc} / \mathrm{s}$ was at least 15 times less frequent, at locations having dip values less than $\pm 2.5^{\circ}$ than at stations having dips of $5^{\circ}$ or more. It seems that the blanketing observed by them was most frequently due to the $c$ - and the $h$-type of 


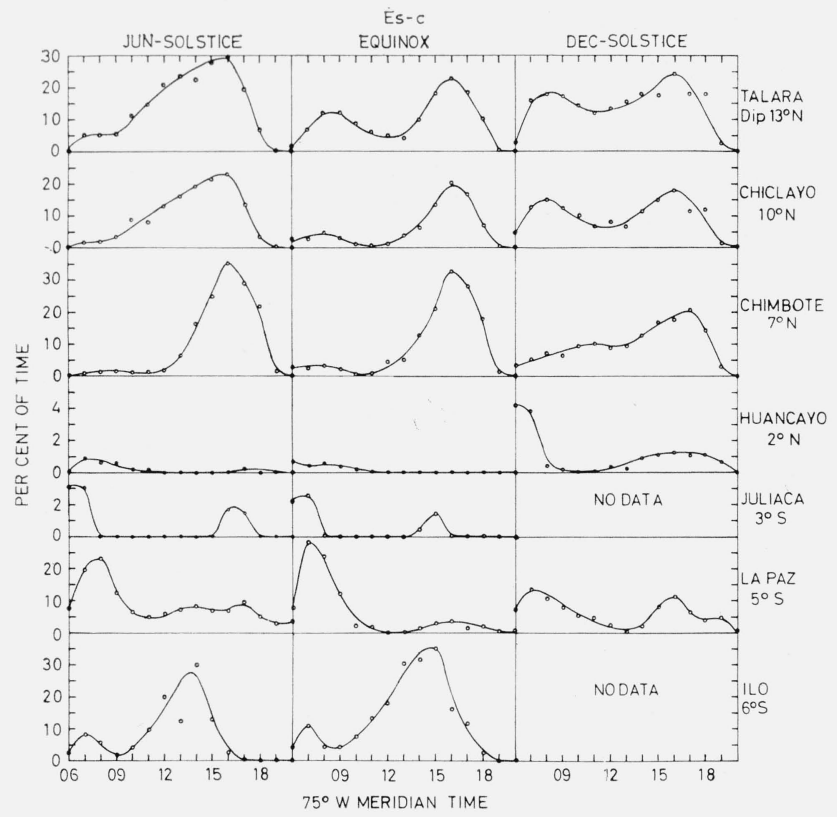

Figure 1. Diurnal variation of Es-c occurrences at different equatorial stations and in different seasons.

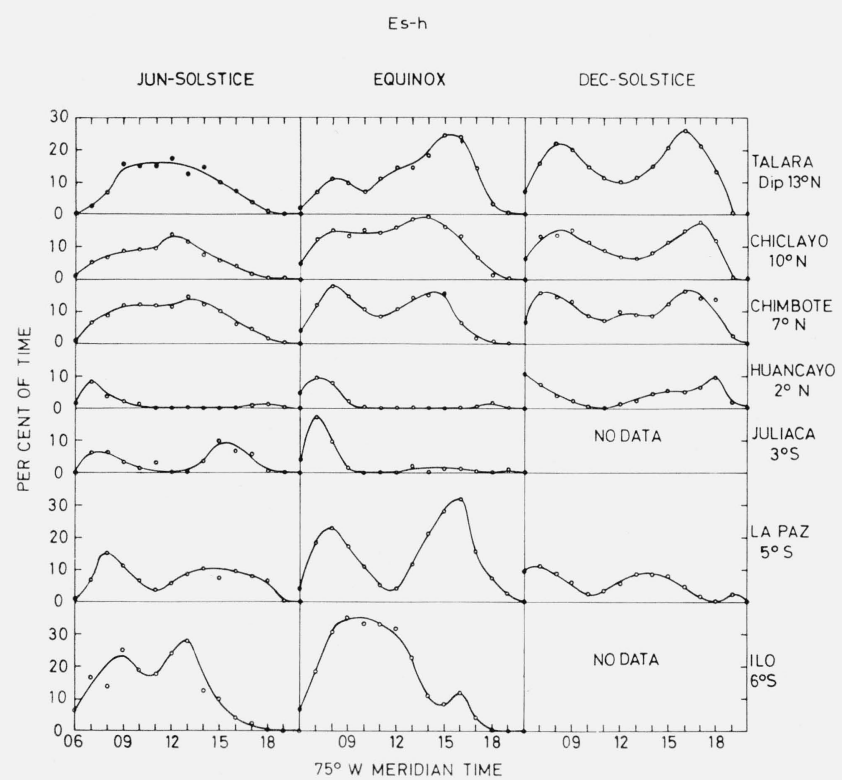

Figure 2. Diurnal variation of Es-h occurrences at different equatorial stations and in different seasons.

sporadic E. From observations of the latitudinal variation of VHF forward scatter via sporadic $E$ irregularities of the magnetic equatorial region Cohen and Bowles [1963b] have also demonstrated the absence of the blanketing sporadic $E$ irregularities at the magnetic equator.

$E s-c$ and $E s-h$ have some features in common. They both produce similar traces showing magnetoionic splitting and are often blanketing. 'The diurnal behavior of their occurrences is also quite similar

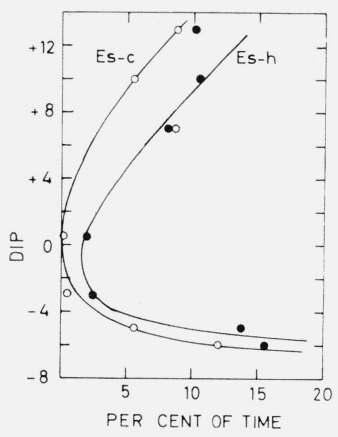

Figure 3. Dependence on dip of the occurrences of Es-c and Es-h near the magnetic equator.

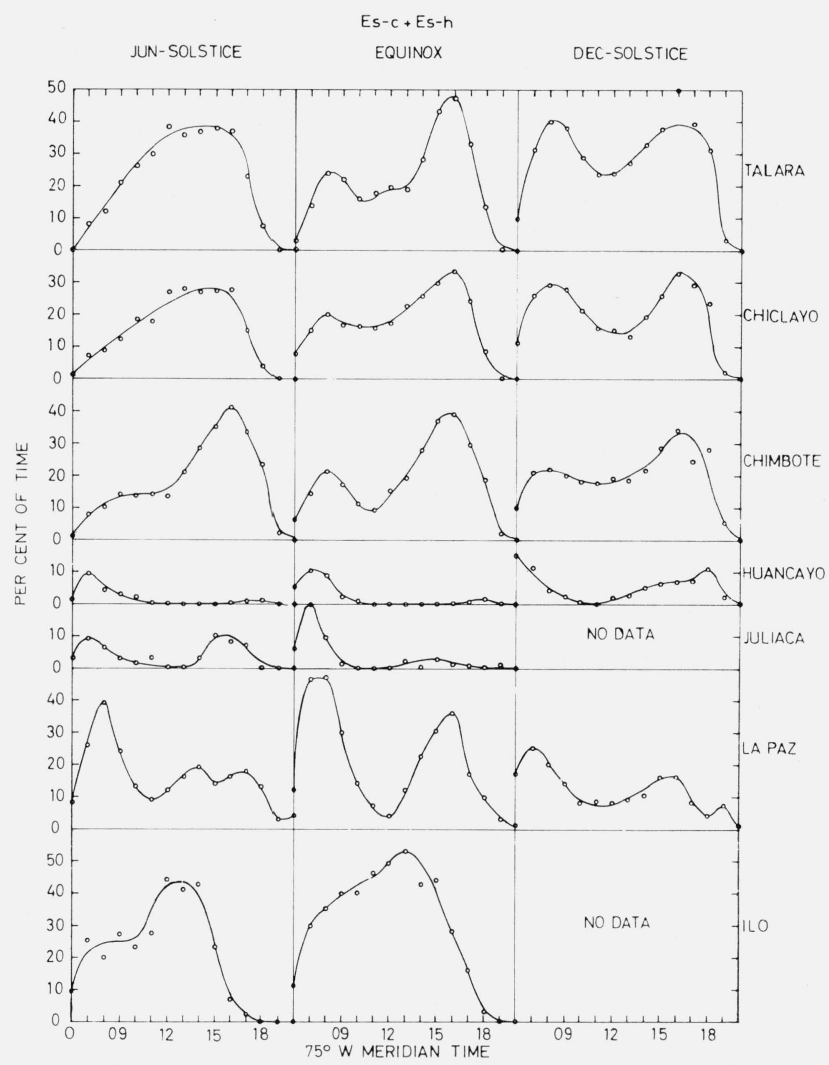

Figure 4. Diurnal variation of (Es-c) + (Es-h) occurrences at different equatorial stations and in different seasons.

(fig. 1 and 2) and they both show similar correlation with dip (fig. 3). It seems likely that these two types have a common origin and so one may examine the hourly variation of the sum of their individual occurrences given in figures 1 and 2 . Figure 4 shows the result. As may be seen from this figure the resultant variation is not much different from the individual variations. Thus it appears that on the whole there is no real basis for distinguishing between these two types. 


\section{Correlation With Geomagnetic Disturbances}

Correlation with geomagnetic disturbances of $E s-c$ and $E s-h$ have been examined by studying the difference between the hourly occurrences on the five internationally quiet days (IQD's) and those on the five internationally disturbed days (IDD's). The results, average of all such days of 1958, are shown in figure 5. It will be observed that there are no significant differences between the hourly occurrences of either type on IQD's (circles) and on IDD's (crosses).

We have also examined whether the ratio of occurrences on IDD's to those on IQD's, for each of the above two types of $E s$, shows any correlation with geomagnetic latitude. Figure 6 shows a plot of the ratio of average hourly occurrence of either type (average of all hourly values given in fig. 5) on IDD's to that on IQD's, against the geomagnetic latitude of the stations. The ratio does not appear to correlate in a significant way with geomagnetic latitude. However, the fact that the value of the ratio for most places is greater than 1.0 suggests that the occurrences of these two types may be slightly greater on disturbed days.
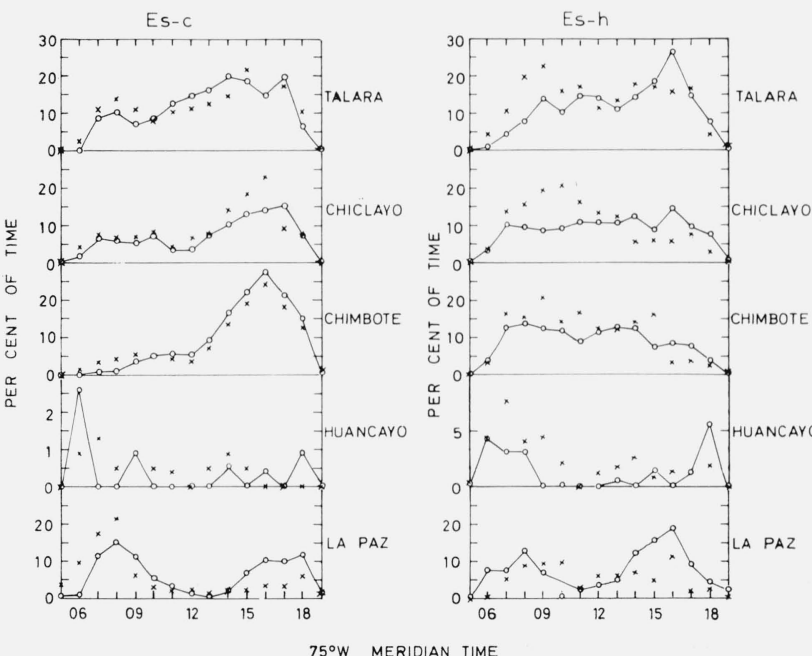

Figure 5. Occurrences of Es-c and Es-h on five internationally quiet and disturbed days during 1958.

Open circles represent quiet day values and crosses, disturbed day values.

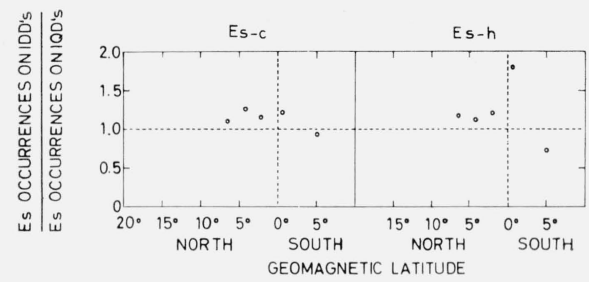

FIGURE 6. Dependence of the ratio of sporadic $\mathrm{E}$ incidence on internationally disturbed days to that on internationally quiet days, against geomagnetic latitude.

\section{Lunar Effects on Es-c and Es-h}

Matsushita [1952, 1953] first found a lunar influence on sporadic $E$. He examined the variation, with lunar time, of the occurrence frequencies of very high $f E s$ values $(f E s>10 \mathrm{Mc} / \mathrm{s})$ as well as of the scaling symbols $G$ and $E$ (indicating occasions of weak or absent $E s$ ) in the hourly $f E s$ tabulation sheets of a number of places. He found two distinct minima in the frequency of occurrences of large $f E s$ values, one around $02 \mathrm{hr}$ and the other around $14 \mathrm{hr}$ of lunar time. These were also the (lunar) hours of most frequent occurrences of the symbols $G$ and $E$.

We have examined similarly the correlation, with lunar hour, of the percentage of time occurrences of the $c$-and the $h$-types of sporadic $E$ at the different equatorial stations. The data examined are those of 1958 for each place except for Juliaca and Ilo, for which only the data of March through May 1959 were available. Figure 7 shows the results. One will find that both $E s-c$ and $E s-h$ at Talara and to some extent at Chiclayo show the type of lunar variation mentioned above, while for other places the results are not so conclusive. The reason why the lunar variation has not come out so distinctly is probably that the frequency of occurrences themselves are very low, and that the data of only a limited period have been available for the study.

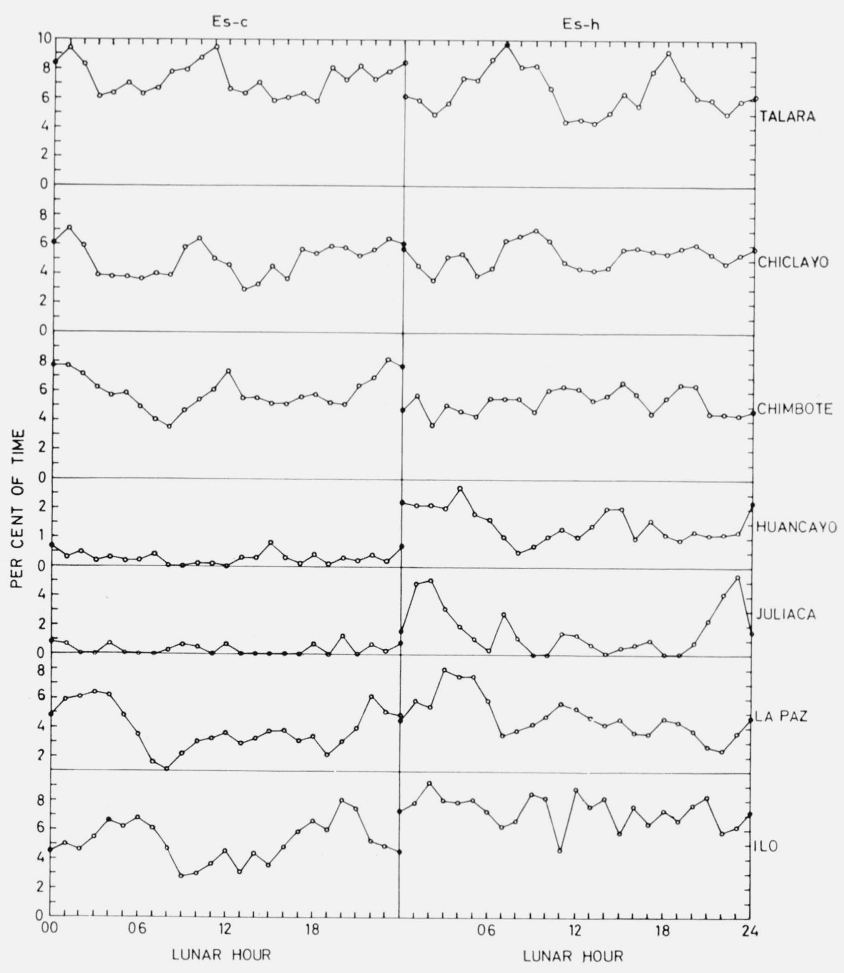

Figure 7. Average percentage of time occurrences of Es-c and Es-h at different lunar hours observed for some equatorial stations. 


\section{Comparison of Sporadic E Observations by Ionosondes With the Results of Equa- torial VHF Forward Scatter Propagation Experiment}

\subsection{The Dato}

One of the NBS equatorial VHF forward scatter propagation paths established in Perú during the IGY, for studying the E-region irregularities, had its 'reflection' point approximately above Huancayo. The data for this transmission path (Arequipa to Trujillo) are, therefore, particularly suitable for comparison with certain features of $E s-q$ and $E s-f$ which have been noted before and described in the earlier work. Particulars of this transmission path are given in table 1 . From the table one may also note the nearness of the path midpoint to Huancayo.

The technique used in the experiment was to transmit a steady 'continuous wave' (CW) signal and to monitor the variations of amplitude of the signal received. Absolute values of the received open circuit antenna voltage, in decibels above 1 microvolt, were tabulated for each 5 minute interval during which a measurement could be made. The decibel scale refers to a receiving antenna matched to a $50 \mathrm{ohm}$ impedance and to a transmitter power of 2 kilowatts. The basic data were read from actual strip-chart recordings and various corrections were applied to yield as near to an absolute signal strength determination as possible.

Besides the variation of the strength of the scatter signal the nature of the traces on the strip-chart records was also found to vary occasionally. Based on their appearances, the traces were divided into five categories-F, M, J, W, and B, indicating respectively fine, meteoric, jagged, wide, and bistatic traces. Details of this classification and its physical significance have been discussed by Cohen and Bowles [1963b]. The above symbols (F, M, etc.) were also tabulated along with the scaled values of the signal strength to describe the kind of trace with which the given value was associated.

\subsection{Diurnal and Seasonal Variations}

Figure 8 shows a comparison between the daytime variation, of the percentage of time occurrences of $E s-q$ at Huancayo (upper frames), and that of the scatter signal strength for the Arequipa-Trujillo path (lower frames), in different seasons during 1958. It may be seen from the figure that shortly after sunrise the scatter signal strength increases in the same way as the $E s-q$ occurrences; both remain at high values for hours around noon, and decrease again in the same manner near sunset. As the parameters compared in figure 8 are different a more quantitative comparison is shown in figure 9. Figure 9(a) illustrates the variation, in different seasons, of the percentage of time $f_{0} \mathrm{Es}$ exceeded the value of $8.0 \mathrm{Mc} / \mathrm{s}$. This high value of foEs during day was almost invariably associated with the $E s-q$ and was reached in the morning at an hour when the average value of the scatter signal was $28 \mathrm{~dB}$. In figure $9(\mathrm{~b})$, therefore, is shown for comparison the percentage of time the scatter signal exceeded the $28 \mathrm{~dB}$ level. Considering that the gain of the ionosonde was neither calibrated nor maintained constant, the agreement would be considered satisfactory.

We have discussed in the earlier paper a seasonal variation of the time of first appearance of $E s-q$ in Huancayo ionograms. It is of interest to see if the VHF scatter signal would also show the same kind of seasonal variation. To compare with the time of first appearance of $E s-q$ we have noted the time in the morning when the scatter signal, growing in intensity, just rises above a given level. Actually, three different levels have been chosen namely, 10 , 15 , and $20 \mathrm{~dB}$. Figure $10(\mathrm{a})$ shows seasonal variation of 30-day running averages (to eliminate the lunar influence discussed in sec. 5.3) of the time of crossing the above levels. The broken curve in the figure depicts the seasonal variation of the sunrise time at $100 \mathrm{~km}$. It may be seen that the seasonal variation of the time of first appearance of signal strength above the given levels do not follow that of the sunrise time, but are characterized by a peak of late appearances around March-April. 'The observed variation, however, agrees closely with the seasonal variation of the hour of first appearance of $E s-q$ in Huancayo ionograms (fig. 11a).

Figure 10(b) similarly shows the seasonal variation of the time near sunset, when the signal strength goes below the given levels $(10,15$, and $20 \mathrm{~dB})$. The observed variations agree with the seasonal variation of sunset time at $100 \mathrm{~km}$ (broken curve of fig. 10b) as well as with that of the time of final disappearance of $E s-q$ from Huancayo ionograms (fig. 11b).

The above similarities in the diurnal behavior (figs. 8 and 9) and in the seasonal variation of the time of first appearance (fig. 11) may be understood on the basis of an explanation involving the equatorial electrojet. Cohen and Bowles [1963a] found that in the morning as the value of $H$, the horizontal

TABLE 1. Particulars of the transmission path

\begin{tabular}{|c|c|c|c|c|c|c|c|}
\hline \multicolumn{4}{|c|}{ Coordinates of } & \multicolumn{2}{|c|}{ Magnetic dip at } & \multirow{2}{*}{$\begin{array}{l}\text { Fre- } \\
\text { quency } \\
\mathrm{Mc} / \mathrm{s}\end{array}$} & \multirow{2}{*}{$\begin{array}{l}\text { Period of } \\
\text { operation }\end{array}$} \\
\hline $\begin{array}{l}\text { Transmitting } \\
\text { site (Arequipa) }\end{array}$ & $\begin{array}{l}\text { Receiving site } \\
\text { (Trujillo) }\end{array}$ & Path midpoint & Huancayo & $\begin{array}{l}\text { Path } \\
\text { midpoint }\end{array}$ & Huancayo & & \\
\hline $\begin{array}{l}16^{\circ} 44.0^{\prime} \mathrm{S}_{\ldots} \\
71^{\circ} 52.5^{\prime} \mathrm{W}_{\ldots}\end{array}$ & $\begin{array}{l}08^{\circ} 6.0^{\prime} \mathrm{S}_{\ldots} \\
79^{\circ} 4.5^{\prime} \mathrm{W}_{\ldots}\end{array}$ & $\begin{array}{l}12^{\circ} 21^{\prime} \quad \mathrm{S} \ldots \\
72^{\circ} 32^{\prime} \quad \mathrm{W}_{\ldots}\end{array}$ & $\begin{array}{l}12^{\circ} 02.7^{\prime} \mathrm{S} \\
75^{\circ} 20.4^{\prime} \mathrm{W}\end{array}$ & $2^{\circ} \mathrm{N}$ & $2^{\circ} \mathrm{N}$ & 49.92 & $\begin{array}{c}7 \text { Dec. } 1957 \\
\text { to } \\
30 \text { Nov. } 1958\end{array}$ \\
\hline
\end{tabular}



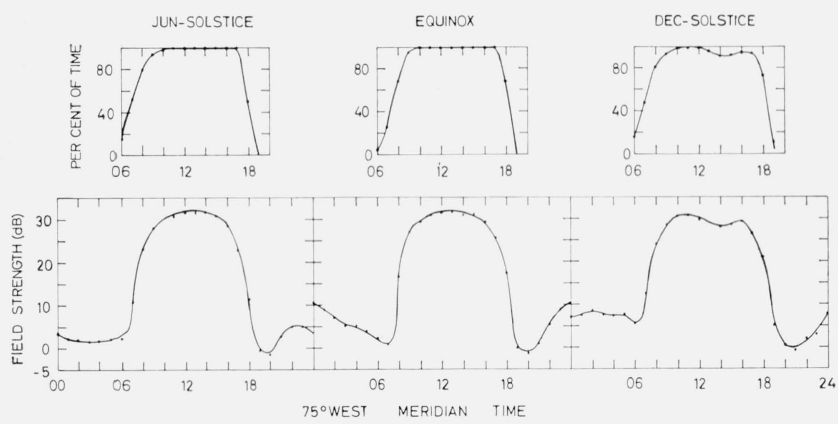

FIGURE 8. Comparison between the diurnal variation of the received field strength for a VHF oblique scatter propagation path which had its reflection point approximately above Huancayo and that of the occurrences of Es-q in Huancayo ionograms.
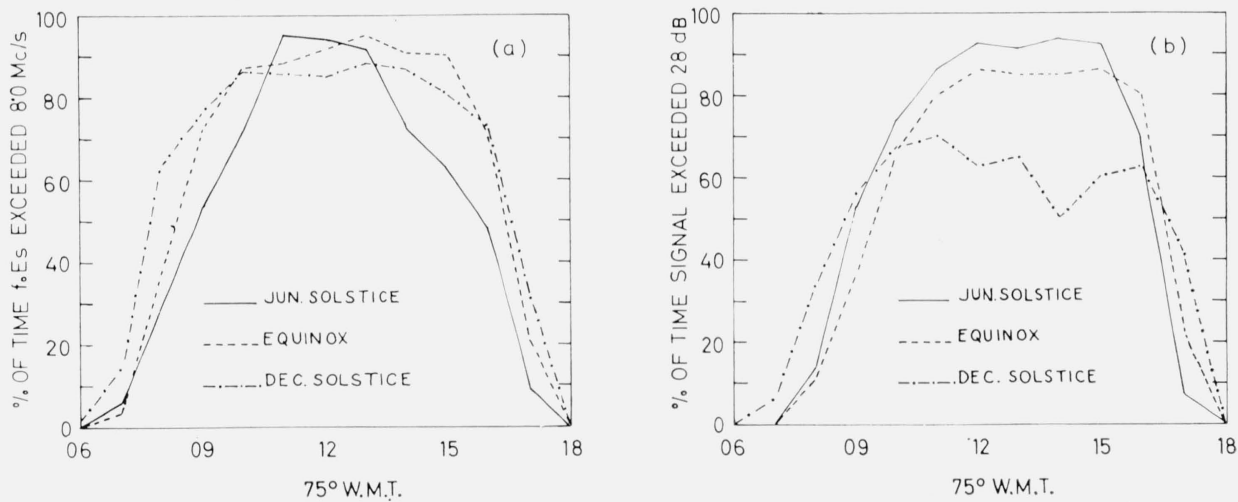

Figure 9. Comparison, in different seasons, between (a) the percentage of time foEs (due to Es-q) exceeds $8.0 \mathrm{Mc} / \mathrm{s}$ and (b) the percentage of time the scatter signal exceeds the $28 \mathrm{~dB}$ level.
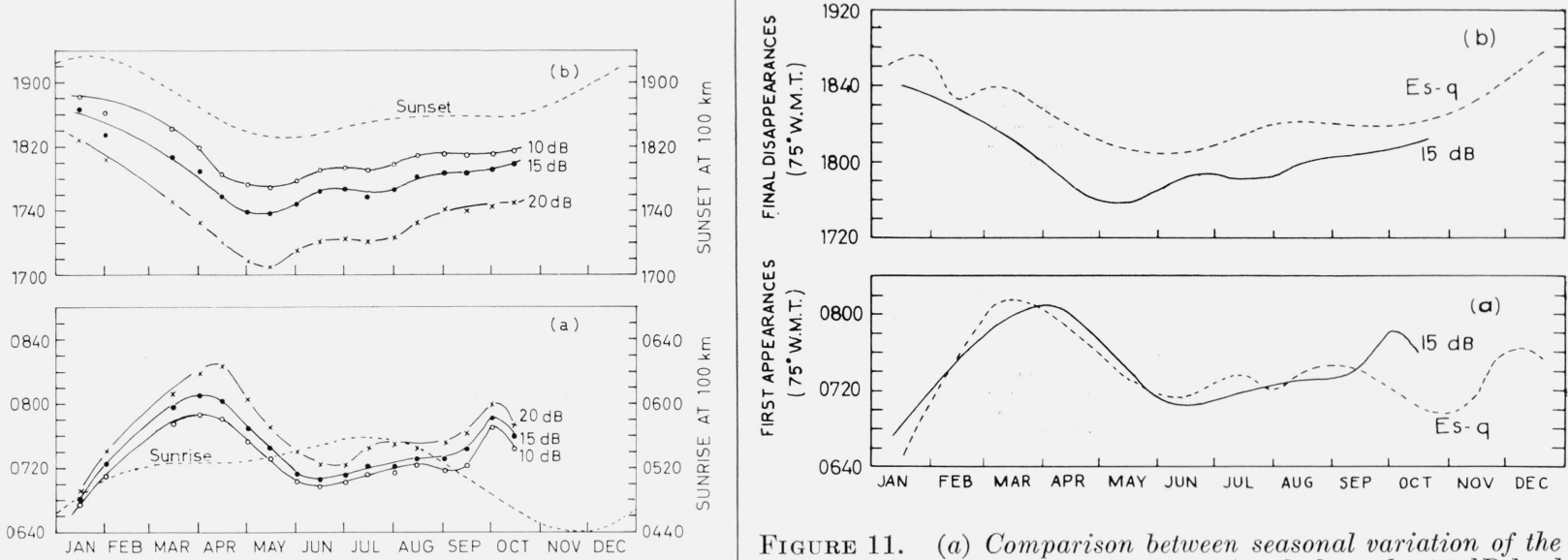

Figure 11. (a) Comparison between seasonal variation of the time of first appearance of scatter signal above the $15 \mathrm{~dB}$ level and that of the time of first appearance of Es-q.

Figure 10. Seasonal variation of the time of first appearance of scatter signal strength above and that of final disappearance below three given levels.

The broken lines in (a) and (b) represent respectively the variaticns of sunrise time and of sunset time at the $100 \mathrm{~km}$ level.

(b) Comparison between seasonal variation of the time of final disappearance of the scatter signal below $15 \mathrm{~dB}$ level and that of the time of final disappearance of Es-g. 
the irregularities which enhance the VHF scatter signal also cause the appearance of the $E s-q$ trace in the ionograms. Further evidences in support of this common origin of the two phenomena are obtained from an examination of the lunar influence and of the effect of sudden $E s-q$ disappearance discussed below.

\subsection{Lunar Correlation}

Some lunar correlation of the VHF forward scatter data for the Arequipa-Trujillo transmission path have been examined as follows. Since the occurrences of different categories of traces ( $F, M$, etc.) indicate probable variations in the propagation mechanism it has been thought proper to examine separately the tabulated values belonging to the different categories of traces. Only the categories $F, M$, and $J$ are considered; the last two $(M$ and $J$ ) are taken together under a single head $T$ (turbulent varieties), because such traces are believed [Cohen and Bowles, 1963b] to be due to the turbulent irregularities familiar in temperate latitude $\mathrm{VHF}$ transmissions. Occurrences of traces of the remaining two categories ( $W$ and $B$ ) being very infrequent are not considered suitable for the analysis.

Traces of the category $F$ have been found to occur both during day and during night. However, only the daytime $F$ category has been found to be closely related to the electrojet and to the appearance of the $E s-q$ traces in Huancayo ionograms. At night the electrojet and its associated irregularities are absent. The nighttime $F$ category, therefore, must be due to irregularities of a different origin. For this reason it has been considered desirable to treat the daytime and the nighttime values of the category $F$, as also of the category $T(=M+J)$, separately. The procedure followed for the lunar analysis is described below.

For each month, either of the two classes of values $F$ and $T$, given at 5 min intervals of solar time, was divided into two groups: daytime values (0600 through 1755 hours) and nighttime values (1800 through 0555 hours). The lunar time corresponding to the $5 \mathrm{~min}$ increments in solar time was computed. For each class the daytime and the nighttime values listed in solar time, were recorded separately under the corresponding $5 \mathrm{~min}$ interval in lunar time. (When two consecutive values belonged to the same lunar interval, the average of the two was taken.) The average of all values belonging to each $5 \mathrm{~min}$ interval of lunar time was then plotted to look for any systematic variation with lunar time. It has been found that except in the case of daytime values of category F, obtained during the December solstice months, a lunar influence is not clearly noticeable. Figure 12 shows the scatter of the average values of category $F$ averaged over the December solstice months and plotted against 5 min intervals of lunar time. In (a) of the figure are shown the daytime values while in (b) are given the nighttime values. A lunar semidiurnal periodicity of the same type as reported by Matsushita (sec. 4) is noticeable in figure $12(\mathrm{a})$, but a similar lunar variation can not be seen in figure $12(\mathrm{~b})$. The lunar semidiurnal variation shown by the daytime values of the $F$ category (fig. $12 \mathrm{a}$ ) is expected since this category of signals has been found to be related to the $E s-q$ and as may be seen from figure 13 (taken from Bandyopadhyay and Montes, [1963]), the $E s-q$ at most equatorial stations exhibits a lunar variation.

Figure 14 shows the kind of average lunar variation noticeable in the case of signals of the turbulent category $T$ obtained during the December solstice months. The daytime values (fig. 14a) show considerable scatter and a systematic variation in lunar time is not recognizable. The scatter of the nighttime values (fig. 14b) is much less and there is some suggestion of a lunar semidiurnal variation of small amplitude. However, we do not know of a mechanism by which the moon may influence turbulence at night and predominantly only during December solstice months.
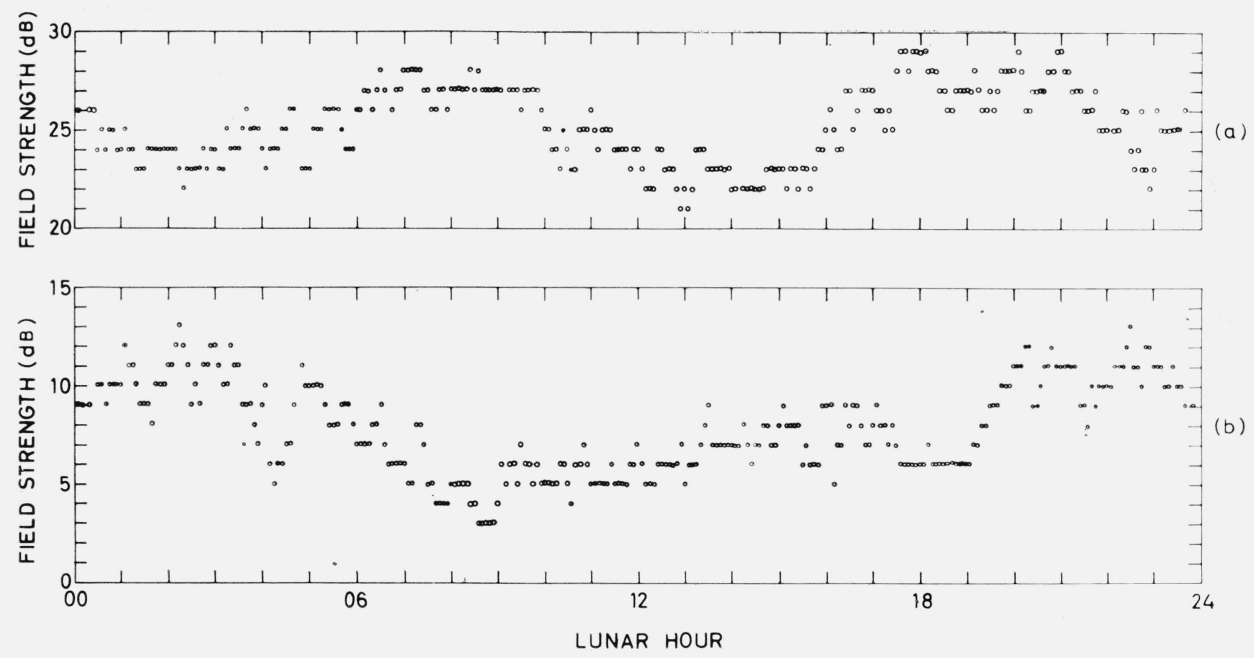

Figure 12. Lunar dependence of the F category of VHF scatter signal during December solstice months.

(a) Daytime values, (b) Nighttime values. 
The fact, suggested by the results of figures 12 (a) and 13 , that both the VHF signal and the $E s-q$ exhibit similar lunar variation, has been confirmed by a number of other comparisons to be described now. It was reported in the earlier paper that the time of first appearance of $E s-q$, as determined from the daily sequence of ionograms at Huancayo, varies considerably from day to day; but when the values are grouped together according to approximate

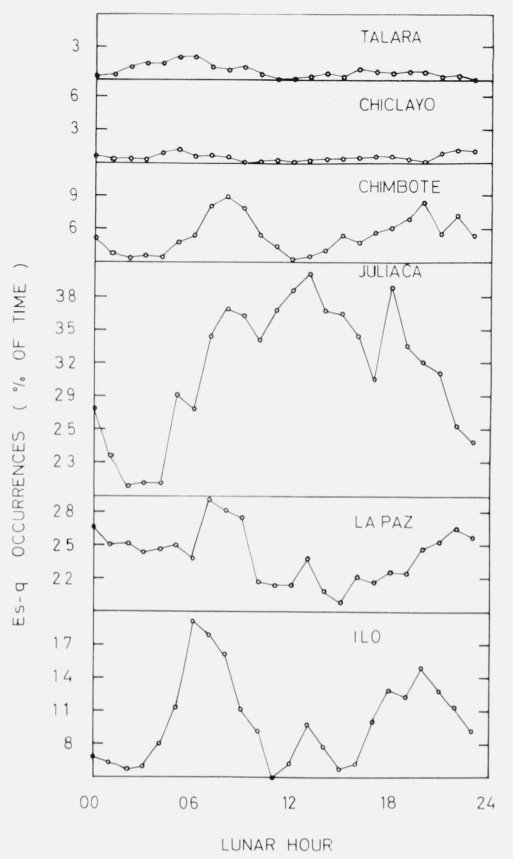

Figure 13. Average percentage of time occurrences of Es-q at different lunar hours observed for some equatorial stations. lunar age of each day and the averages for the different lunar ages are determined from a sufficiently large number of lunations, the values show distinct lunar periodicity (fig. 15b). The time of final disappearance of $E s-q$ near sunset, when treated similarly, did not however show any such lunar influence (fig. 15a). To compare with the above results we have examined in a similar way the VHF forward scatter data for the lunar influence. The time of first appearance of $E s-q$ has been considered to correspond to that of the first appearance of scatter signal strength above a given level (in the same way as described in sec. 5.2 for making the comparison of fig. 11). The time of final disappearance of $E s-q$ near sunset has been made to correspond similarly to the time of final going down of the signal strength below the given level. The dependence on lunar age,
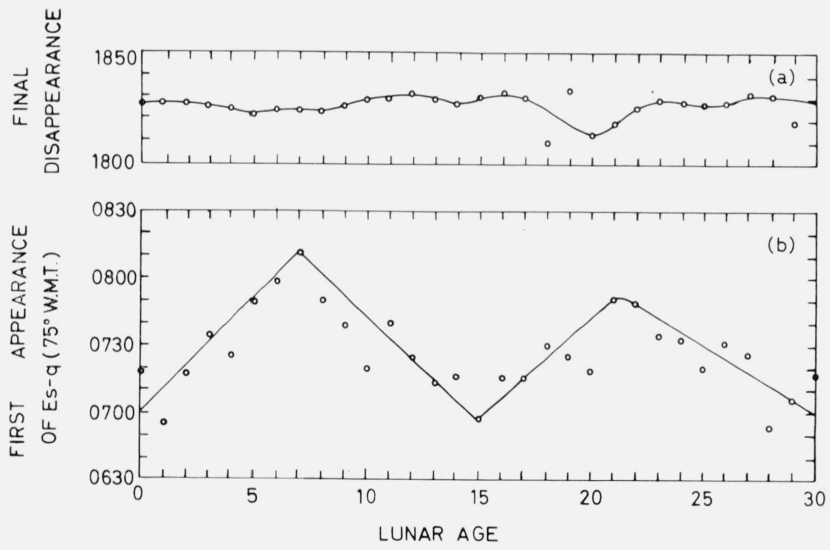

FiguRE 15. Variation with lunar phase of the average time of (a) final disappearance and of (b) first appearance of Es-q at Huancayo.

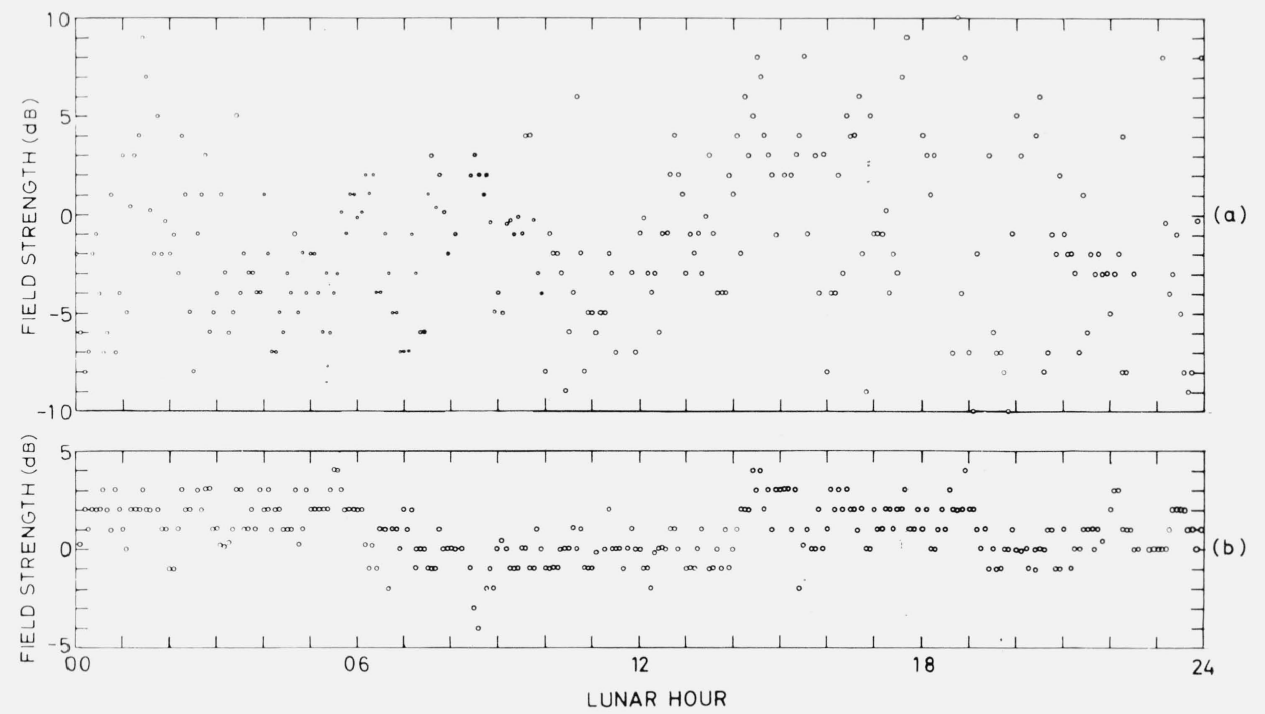

Figure 14. Lunar dependence of the $\mathrm{T}(=\mathrm{M}+\mathrm{J})$ category of VHF scatter signal during December solstice months.

(a) Daytime values, (b) Nighttime values. 
of the average time (averaged over the lunar months of 1958) of first appearance of signal strength above 10 and $15 \mathrm{~dB}$ levels is shown in figure 16 . Although there is considerable spread of the points, particularly at higher values of the lunar age, the type of variation indicated by the full line curve is generally recognizable. It shows the same kind of lunar dependence as depicted in figure 15(b).

Figure 17 shows the average variation, against lunar age, of the time when near sunset the signal strength goes below either of the same two levels $(10$ and $15 \mathrm{~dB})$. It will be observed that the kind of lunar influence noticeable in figure 16 is not evident here. The fluctuations in figure 17 are rather irregular and of much smaller amplitude. The situation, however, is quite similar to that of figure 15 (a).

In deriving the results of figures 16 and 17 some fixed signal levels were chosen and the lunar influence was sought in the day-to-day variation of the time when the scatter signal rose above (or went below) these levels. A complementary way of observing the same effect is to keep the time fixed, the lunar influence being looked for in the day-to-day fluctuation of the signal strength for a fixed time of day. Actually two different hours in the morning (0900 and $1000 \mathrm{hr}$ ) and two in the afternoon (1700 and $1800 \mathrm{hr}$ ) were selected. The average variations,

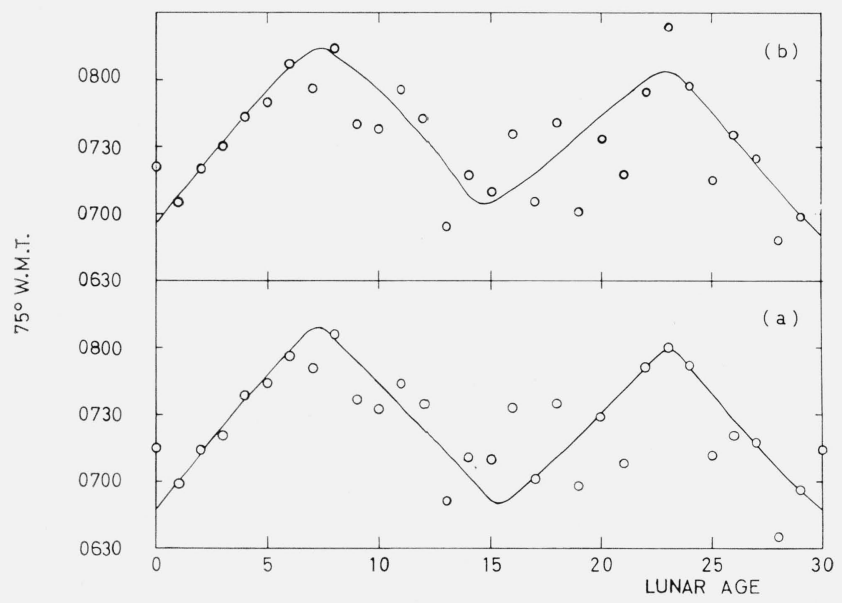

FIguRE 16. Variation with lunar phase of the average time of first appearance of the scatter signal above (a) $10 \mathrm{~dB}$ level and $(b) 15$ dB level.

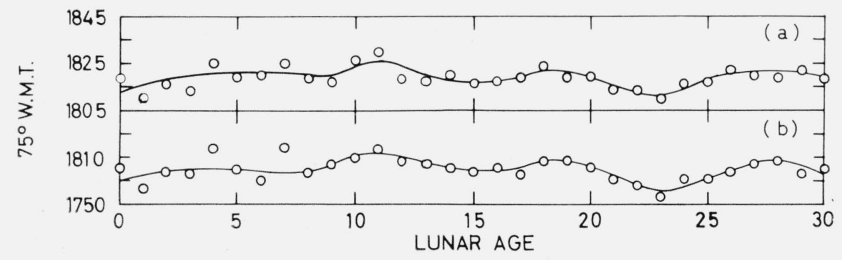

FiguRE 17. Variation with lunar phase of the average time of final disappearance of scatter signal below (a) $10 \mathrm{~dB}$ level and $(b) 15$ dB level. against lunar age, of signal strength at the two morning hours and at the two afternoon hours, determined in the same way as with figures 16 and 17 , are shown in figures 18 and 19 , respectively. Figure 18 shows two fairly distinct minima around the first and the third quarter of the moon, while figure 19 does not show conclusively any lunar effect. The figures 18 and 19 thus confirm the results of figures 16 and 17 , respectively.

The lunar influences discussed above may be understood on the basis of an explanation originally due to Matsushita [1957]. Having suggested that the cause of the $E s-q$ is the eastward flowing current of the daily magnetic variation (equatorial electrojet), he pointed out that while the solar current flows eastward throughout the day, the lunar current (more precisely, the lunar electric field tending to produce the current), having semidiurnal periodicity, may act eastward or westward depending on the lunar hour. Now, the semidiurnal periodicity of the lunar field is such that it acts westward during the hours $00-06$ and $12-18$ of lunar time [Chapman and Bartels, 1940]. Around the first and third quarter of the moon the above two lunar hour intervals correspond to the early morning hours in solar time, when the eastward solar electrojet begins to flow. One would, therefore, expect that around these lunar ages, under the opposing influence of the lunar field, the hour at which the resultant eastward current would rise above the threshold value, envisaged in Farley's theory (sec. 5.2) for the instability to set in, will be delayed.

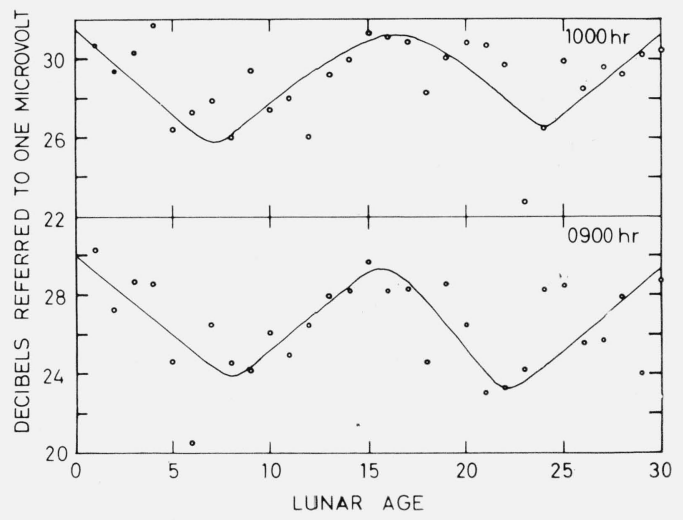

FIGURE 18. Variation with lunar phase of the average signal strength at two fixed (solar) hours near sunrise.

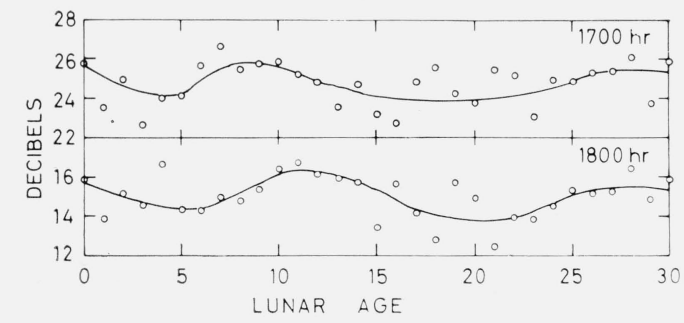

FiguRE 19. Variation with lunar phase of the average signa strength at two fixed (solar) hours near sunset. 
Consequently, the first appearance of $E s-q$ as well as that of the scatter signal above a given level will also be delayed. Again, on the same reasoning, adhering to a fixed solar hour near sunrise and observing the dependence of the scatter signal strength at the given hour on lunar age, one would expect to find lower signal levels around these lunar ages (first and third quarter). The results of figures $15(\mathrm{~b}), 16$, and 18 are in accord with these expectations.

However, the same mechanism requires that near sunset one would also find some lunar influence on the corresponding parameters namely, the time of final disappearance of $E s-q$, that of final going down of signal strength below given levels and the strength of signal at a given hour in late afternoon. These have been examined in figures 15 (a), 17, and 19, respectively. The results, however, do not show the expected lunar influence (at least to the same degree as shown by their early morning counterparts). The cause of this is not clear.

Bhargava [1963] has reported the results of his examination of the lunar influence in the $E s-q$ data of the equatorial station of Kodaikanal (magnetic latitude $1.75^{\circ} \mathrm{N}$ ), India. He found that the average time of first appearance of $E s-q$ in the ionograms of Kodaikanal depends on lunar phase, being earlier around new and full moon. The lunar effect found by him on the time of final disappearance of $E s-q$, however, can be seen to be much less. His observations during the winter months (over the period September 1955-August 1960) do not show the lunar effect conclusively. Only during the equinox months the effect is prominent; but the difference between the average time of final disappearance of $E s-q$ around new (or full) moon and that around the first (or the third) quarter is only about $10 \mathrm{~min}$, whereas the same difference found by him in the case of the hour of the first appearance of $E s-q$ (during the winter months) is quite large (about $34 \mathrm{~min}$ ).

\subsection{Sudden Es-q Disappearances and Simultaneous Decrease of Scatter Signal Strength}

The $E s-q$ which is a steady feature of daytime ionograms at Huancayo (being present more than 95 percent of the time) is sometimes found to disappear suddenly for periods extending from a few minutes to a few hours. This phenomenon has been examined by a number of workers [Matsushita, 1957; Knecht, 1959 ; Bandyopadhyay and Montes, 1963]. It seems likely that the moon, acting in the same manner as discussed in the preceding section, weakens the solar electrojet, on these occasions, so much that the strength of the latter falls below the threshold value required for the formation of the irregularities. One would, therefore, expect to find a decrease in the strength of the scatter signal simultaneously with the $E s-q$ disappearance. This is exactly what has been observed. Figure 20 is a typical example illustrating the correspondence. The filled circles near the bottom of the figure indicate, as in $f$-plots, the occurrences of $E s-q$ in the

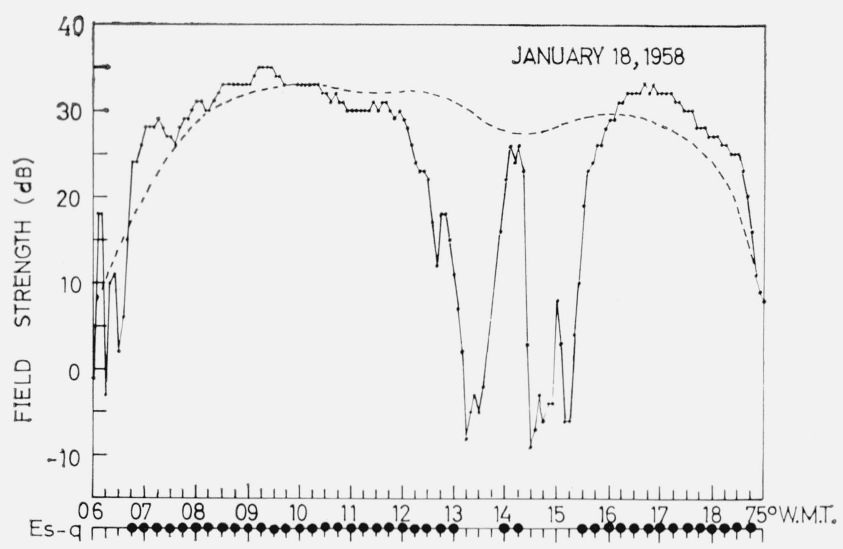

Figure 20. Typical correspondence between sudden Es-q disappearance and simultaneous decrease of field strength.

The broken curve shows the average variation of field strength during January 1958.

quarter-hourly ionograms obtained at Huancayo. The points within the figure (joined by straight lines) indicate the values of the field strength on the day of comparison, while the broken curve indicates the monthly median values. The figure shows two Es-q. disappearances, one between 1300 and $1400 \mathrm{hr}$ and the other between 1415 and $1530 \mathrm{hr}$, both of which correspond closely with very large drops of the received signal strength. Such correspondence has been noticed for all the observed $E s-q$ disappearances, without exception.

\subsection{Nighttime Variations}

In view of the correspondences observed during daytime between Es-q occurrences and signal strength fluctuations (figs. 8 and 9) one may also look for similar correspondence, if any exists, between nighttime signal strength fluctuation and the occurrences of $E s-f$, the only nighttime type of sporadic $E$ at Huancayo. Figures 21 and 22 , obtained in the same way as figures 8 and 9 respectively, show the comparison. The close similarity noticeable between the two groups of curves suggests that the same kind of irregularities manifests in the records. On individual nights, however, unlike with $E s-q$ disappearance and simultaneous decrease of scatter signal strength, no one-to-one correspondence can always be found between the occasions when no $E s-f$ is observed in Huancayo ionograms and low values of signal strength occur. Figure 23, drawn on the same scheme as figure 20 , illustrates this.

\section{Discussion}

A close agreement has been observed between the daytime fluctuations of the VHF scatter signal for the Arequipa-Trujillo path (path midpoint above Huancayo) and the Es-q occurrences in Huancayo ionograms. The agreement is noticeable in the diurnal and seasonal variations and in the lunar influences, 


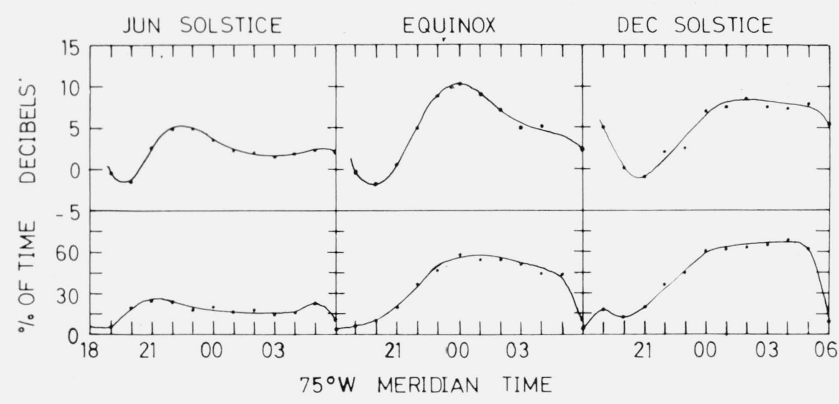

Figure 21. Comparison between the nighttime variation of the received field strength for a VHF oblique scatter propagation path which had its reflection point approximately above Huancayo and that of the percentage of time occurrences of Es-f in Huancayo ionograms.
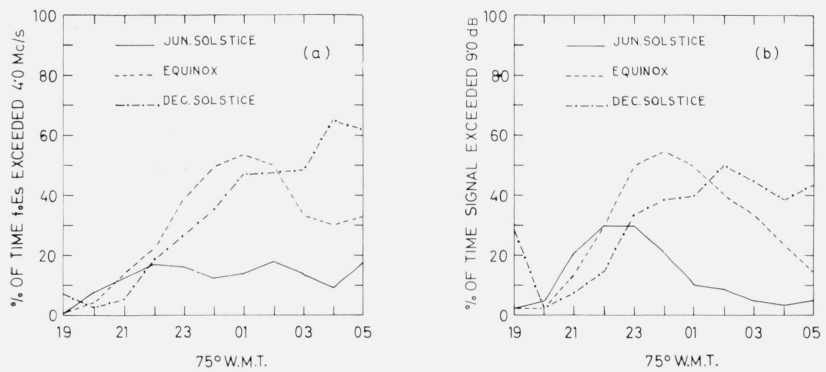

Figure 22. Comparison, in different seasons, between (a) the percentage of time foEs (due to Es-f) exceeds $4.0 \mathrm{Mc} / \mathrm{s}$ and $(b)$ the percentage of time the scatter signal exceeds the 9 dB level.

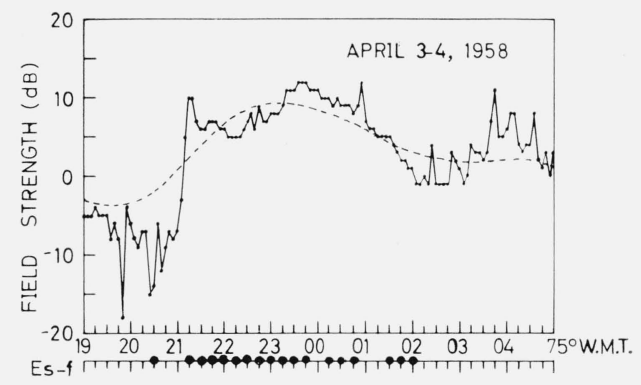

FIGURE 23. Es-f occurrences and field strength variation on a typical night when there is no correspondence between the two.

The broken curve shows the average variation of field strength during April 1958.

as well as during the occurrence of the phenomenon of sudden $E s-q$ disappearance. As has been mentioned already (sec. 5.2), the above agreement between the ionosonde observations and the VHF scatter can be generally understood from the theory of Farley [1963]. A more quantitative tie-in between the two kinds of observations, however, might be expected on the basis of the same theory. An oblique incidence frequency $f$, on which the VHF scatter is observed, corresponds to a vertical incidence frequency $f_{\mathrm{v}}$ given by $f_{\mathrm{v}}=f \sin \theta / 2$ where $\theta$ is the scattering angle. With the present observations $f$ was about $50 \mathrm{Mc} / \mathrm{s}$ and $\theta$ was approximately $22^{\circ}$. This means an equivalent vertical incidence frequency, $f_{\mathrm{v}}$, of about $10 \mathrm{Mc} / \mathrm{s}$. It follows, therefore, that the VHF scatter observations on $50 \mathrm{Mc} / \mathrm{s}$ and the ionosonde observations on $10 \mathrm{Mc} / \mathrm{s}$ should be related through the same threshold strength of the electroject stream. In other words, one should expect that, on a given day, the strength of the electrojet (as indicated by $\dot{H}$ ) at the time of first appearance of $\mathrm{fEs}$ above $10 \mathrm{Mc} / \mathrm{s}$ on the ionogram should be the same as that observed when VHF scatter on $50 \mathrm{Mc} / \mathrm{s}$, by $E s-q$ irregularities, is first established in the morning.

Now, examination of ionograms show that the value, $10 \mathrm{Mc} / \mathrm{s}$, of $f E s$ is a fairly high one and, if reached at all, occurs late in the morning. However, the first indications of VHF scatter by $E s-q$ irregularities (such as the occurrence of traces of the $F$ category) are noticed quite early (around sunrise). Obviously, therefore, the two kinds of observations are not in quantitative agreement with the above prediction from Farley's theory. However, the lack of agreement is most probably due to the low sensitivity of the ionosonde. Under the circumstances, the best quantitative agreement that one could observe is what has been shown in figure 9. At a certain hour in the morning (in other words, corresponding to a given value of the strength of the electrojet) when the most frequent value of $f E s$ is $8 \mathrm{Mc} / \mathrm{s}$ it is found that the most frequent value of the VHF scatter signal is $28 \mathrm{~dB}$. The figure shows that the percentage of time $f E s$ exceeds $8 \mathrm{Mc} / \mathrm{s}$ at different hours of the day is in fair agreement with that of the time the VHF signal exceeds the $28 \mathrm{~dB}$ level.

At night the electrojet is absent and so are the associated irregularities. However, some other kind of irregularities must be present to account for the high value of the scatter signal observed at night. One likely explanation of the existence of correspondence between the average behavior of the nighttime scatter signal and that of the $E s-f$ occurrences (figs. 21 and 22) and lack of same on many individual nights (fig. 23) is that the nighttime sporadic $E$ ionization, examined above, is of a patchy nature. The antenna system of the ionosonde and that of the oblique scatter experiment did not view exactly the same volume and the scattering geometry in the two cases was probably different. Hence it is not expected that ionized patches of limited extent would always be found simultaneously on the two systems. The inclusion of a large common scattering volume by the two systems, however, would ensure similarity in the average behavior.

An alternative explanation may be the limited sensitivity of the ionospheric sounder: the ionosonde was not designed to look at the weak scattering irregularities.

We acknowledge our sincere gratitude to Ing. Albert A. Giesecke, Jr., for his keen interest and constant encouragement throughout the progress of the work. We are indebted to Dr. Robert Cohen and Dr. K. L. Bowles for making available to us 
data from their equatorial VHF forward scatter experiment, as also for many helpful discussions. Our grateful thanks are due to Mr. James Winkelman of CRPL, Boulder for the computer programming of the lunar analysis described in section 5.3. Assistance in calculation and other help from Mr. A. Morales and Mr. F. Domínguez are also thankfully acknowledged.

\section{References}

Bandyopadhyay, P., and H. Montes (1963), Some apsects of Es ionization of the magnetic equatorial region, J. Geophys. Res. 68, 2453-2484.

Bhargava, B. N. (1963), Lunar tidal effects in equatorial Es, J. Atmospheric Terrest. Phys., 25, 367-370.

Bowles, Kenneth L., and Robert Cohen (1962), A study of radio wave scattering from sporadic $E$ near the magnetic equator, in Ionospheric sporadic E., E. K. Smith Jr. and S. Matsushita, eds.pp. 51-77 (Pergamon Press, New York, N.Y.)

Bowles, K. L., B. B. Balsley, and Robert Cohen (1963), Field-aligned E-region irregularities identified with acoustic plasma waves, J. Geophys. Res. 68, 2485-2501.

Chapman, S., and J. Bartels (1940), Geomagnetism (Clarendon Press, Oxford).
Cohen, Robert, and Kenneth L. Bowles (1963a), The association of plane-wave electron-density irregularities with the equatorial electrojet, J. Geophys. Res. 68, 2503-2525.

Cohen, Robert, and Kenneth L. Bowles (1963b), Ionospheric VHF scattering near the magnetic equator during the International Geophysical Year, J. Res. NBS. 6rD, (Radio Prop.) No. 4, 459-480.

Cohen, Robert, Kenneth L. Bowles, and Wynne Calvert (1962), On the nature of equatorial slant sporadic $E$, J. Geophys. Res. 6\%, 965-972.

Farley, D. T. Jr. (1963), Two-stream plasma instability as a source of irregularities in the ionosphere, Phys. Rev. Ltrs. 10, 279-282.

Knecht, R. W. (1959), An additional lunar influence on equatorial Es at Huancayo, J. Atmospheric Terrest. Phys. 14, $348-349$.

Knecht, R. W., and R. E. MeDuffie (1962), On the width of the equatorial Es belt, in Ionospheric Sporadic $E$, E. K. Smith, Jr., and S. Matsushita, eds., pp. 215-218 (Pergamon Press, New York, N.Y.).

Matsushita, S. (1952), Semidiurnal lunar variation in sporadic E, J. Geomag. Geoelect. 4, 39-40.

Matsushita, S. (1953), Lunar tidal variations in the sporadic $E$ region, Rept. Ionospheric Res. Japan $\boldsymbol{\gamma}, 45-52$.

Matsushita, S. (1957), Lunar effects on the equatorial Es, J. Atmospheric Terrest. Phys. 10, 163-165.

(Paper 68 D 11-427) 